\title{
Percutaneous transbiliary biopsy
}

\section{Biópsia percutânea transbiliar}

Gustavo Vieira Andrade"; Miguel Arcanjo Santos; Marconi Roberto Meira'; Mateus Duarte Meira'.

\section{A B S T R A C T}

Percutaneous drainage of the bile ducts is an established procedure for malignant obstructions, in which a histological diagnosis is often not obtained. We describe the biopsy technique of obstructive lesions through biliary drainage access, using a $7 F$ endoscopic biopsy forceps, widely available; some are even reusable. This technique applies to lesions of the hepatic ducts, of the common hepatic duct and of all extension of the common bile duct.

Keywords: Jaundice, Obstructive. Biliary Tract Neoplasms. Biopsy.

\section{INTRODUCTION}

$\mathrm{M}$ alignant obstructions of the bile ducts are part of the routine abdominal surgery services, often with extreme difficulty in cytological or histological diagnosis, especially in the high lesions. In these, drainage of the bile duct by trans-hepatic percutaneous access (PTBD) is performed routinely. However, few services perform cytological investigation with a brush or even biopsy of the obstruction by this access, delaying or preventing specific oncological treatment $t^{1,2}$.

In a large number of biliary lesions, size and location impede percutaneous access for biopsy and fragment removal for histopathological study ${ }^{3,4}$. Access through the biliary tract allows cytological examination of bile with a brush, but with low sensitivity and low availability. The forceps biopsy through the PTBD access is very little known in Brazil, and the technique described uses the more expensive and not widely available myocardial biopsy forceps ${ }^{3}$. In this paper, we describe the modified technique with a wired introducer sheath and an endoscopic gastric biopsy forceps, available at endoscopy services.

\section{TECHNICAL NOTE}

At the same time of the drainage or later, with the trans-hepatic access made, under prophylactic antibiotic therapy, we perform a cholangiography,

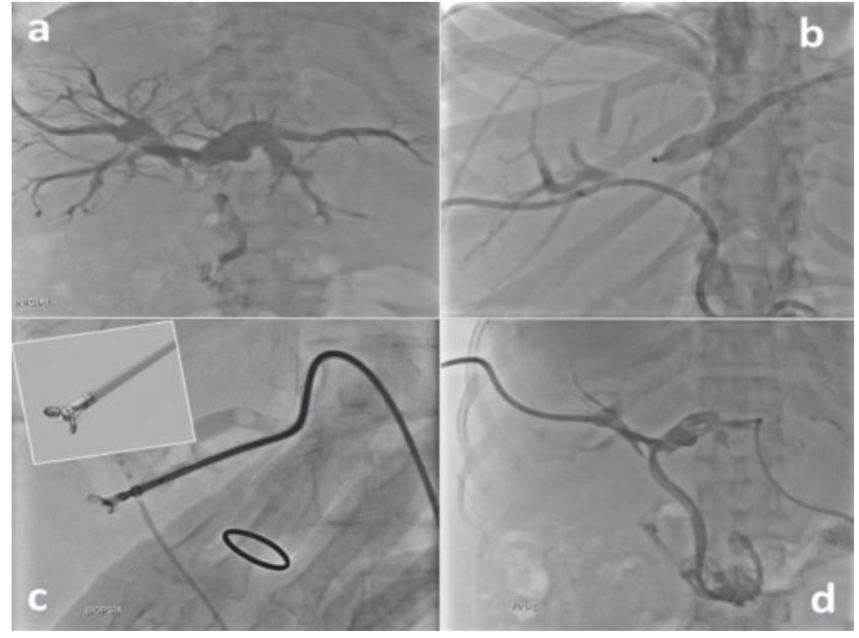

Figure 1. A) Cholangiography with dilatation of the bile ducts and obstruction in the confluence of the hepatic ducts; B) Operator's hand keeping the sheath against the obstruction; C) Detail of the forceps used with a spike; D) The obstruction is crossed and two internal-external drains are placed.

identifying the site of the obstruction (Figure 1a). Under fluoroscopic guidance, we introduce a guidewire down to the point of obstruction and, over this, a $7 \mathrm{~F}$ to $10 \mathrm{~F}$ sheath, together with the dilator. Our preference is for a wired sheath that fits the curves better and does not kink. Wherever possible, we use the Flexor Ansel Sheath or Raabe Sheath short models. Once positioned within the obstruction, we keep the sheath firm and remove the guidewire and dilator (Figure $1 \mathrm{~b}$ ). We then introduce the $7 F$ endoscopic biopsy forceps catheter, which has some reusable models. It is worth mentioning that there are models with needle or spike, with alligator type blades, among others. All can be used, however,

1 - Restoration Hospital, Department of Abdominal Surgery, Recife, Pernanmbuco State, Brazil. 
because they are available in our service, we use the Capture Biopsy Forceps With Spike more often (Figure 1c). Under fluoroscopy, we introduce the forceps until it is out of the sheath and open it. With the forceps open, we push the set (sheath and catheter-forceps) towards the obstruction and, with an auxiliary maintaining positive pressure of the set against the injury, we close the forceps, thus necessitating four hands for execution. Still holding the sheath in the same place, we remove the forceps, macroscopically explore the material and place it in formalin, preferably buffered. We repeat the maneuver as many times as necessary until we obtain a satisfactory sample for the histological study, on average four to five times. Finally, we cross the obstruction with the guidewire, remove the sheath and introduce a biliary drain of thickness similar or superior to the sheath used (Figure $1 \mathrm{~d}$ ). If we can not overcome the obstruction, we place an external drain, also of similar or larger diameter than the sheath. We wash the biliary tree and, if the drain is internal, we leave the external drainage open for 24 hours. In the external drains, it has to be kept open.

\section{DISCUSSION}

As we have seen, it is a simple technique and quite similar to that already published with myocardial forceps ${ }^{3,4}$, but with a cheaper device, much more available in surgery services, and with some models authorized for reuse. Another great advantage is the possibility of biopsying lesions in the hepatic ducts, in the common hepatic duct or in the common bile duct, even in patients with intestinal or bilio-digestive derivations.

The presence of the pathologist in the room is of great value, but it is not the rule in many services. As patients remain with biliary drains, access is ready for repeating the biopsy when and if necessary. After about one or two weeks, if the result is inconclusive, everything can be repeated on an outpatient basis. Without a pathologist in the room, we obtained a positive result in $60 \%$ in the first procedure, reaching more than $80 \%$ after the second.

A simple and easily available technique, it allows the approach of high or low biliary obstructive lesions, speeding up and optimizing the onset of treatment.

\title{
R E S U M O
}

\begin{abstract}
A drenagem percutânea das vias biliares é um procedimento estabelecido para obstruções malignas, nos quais, muitas vezes, não se consegue um diagnóstico histológico. Descrevemos a técnica de biópsia da lesão obstrutiva através do acesso de drenagem biliar, utilizando um fórcipe de biópsia endoscópica 7F, amplamente disponível e alguns reutilizáveis. Esta técnica aplica-se a lesões dos ductos hepáticos, do hepático comum e de toda extensão do colédoco.
\end{abstract}

Descritores: Biópsia Guiada por Imagem. Neoplasias dos Ductos Biliares. Icterícia Obstrutiva.

\section{REFERENCES}

1. Xing GS, Geng JC, Han XW, Dai JH, Wu CY. Endobiliary brush cytology during percutaneous transhepatic cholangiodrainage in patients with obstructive jaundice. Hepatobiliary Pancreat Dis Int. 2005;4(1):98-103.

2. Tsai CC, Mo LR, Chou CY, Han SJ, Lin RC, Kuo JY, et al. Percutaneous transhepatic transluminal forceps biopsy in obstructive jaundice. Hepatogastroenterology. 1997;44(15):770-3.

3. Jung GS, Huh JD, Lee SU, Han BH, Chang HK, Cho YD. Bile duct: analysis of percutaneous transluminal forceps biopsy in 130 patients suspected of having malignant biliary obstruction. Radiology. 2002;224(3):725-30.
4. Li Z, Li TF, Ren JZ, Li WC, Ren JL, Shui SF, et al. Value of percutaneous transhepatic cholangiobiopsy for pathologic diagnosis of obstructive jaundice: analysis of 826 cases. Acta Radiol. 2017;58(1);3-9.

Received in: 05/11/2016

Accepted for publication: 15/12/2016

Conflict of interest: none.

Source of funding: none.

\section{Mailing address:}

Gustavo Vieira Andrade

E-mail: guga.andrade@gmail.com

andradegus@msn.com 